\section{Privacidade e confidencialidade como princípios em bioética: é possível violar sem quebrar a confiança na perspectiva das informações pessoais?}

\section{Nascimento, Milton Luiz}

Programa de Pós-Graduação em Bioética, Cátedra Unesco de Bioética da Universidade de Brasília - UnB. E-mail: mylthon@hotmail.com

PALAVRAS CHAVE: privacidade; confidencialidade; bioética; violação.

Introdução: Em meio as situações persistentes que se repetem e situações emergentes que aparecem com o avanço do desenvolvimento dos últimos cinquenta anos surgem questionamentos de natureza ética que ocorrem no cotidiano relacionado ao princípio de privacidade e confidencialidade. $\mathrm{O}$ artigo $9^{\circ}$ da Declaração Universal Sobre Bioética e Direitos Humanos da Organização das Nações Unidas para Educação, a Ciência, a Cultura prevê concentrar o máximo esforço na proteção das informações coletadas que possam garantir a privacidade e confidencialidade. Método: Estudo de revisão bibliográfica do conceito de privacidade e confidencialidade relacionados a bioética. Resultados: O interesse de proteger a privacidade não é um tema novo. Possui vários fatores e um histórico bem definido. Uma das principais características é reconhecer a privacidade como um direito humano fundamental. Os filósofos descreveram a privacidade como uma característica indispensável da liberdade pessoal. Confidencialidade refere-se a uma relação especial de confiança entre pessoas, presume que as informações compartilhadas permaneçam em segredo, e não devem ser divulgados a terceiros, a menos que um interesse estritamente definido. O pacto pela confidencialidade só é compreendido quando as informações são dadas de modo voluntário e consciente. A confiança não ocorre a menos que envolva indivíduos racionais, conscientes e livres. Há uma uniformidade entre os autores pesquisados que a privacidade e confidencialidade precisam ser respeitadas e que esse princípio deve ser estendido até mesmo após a morte do indivíduo. A confidencialidade não é intocável, mas mesmo assim deve ser tratada com cuidado quando há necessidade de violação. Esse cuidado deve levar em conta a promoção do melhor interesse do indivíduo, a sua segurança, o bemestar de outras pessoas envolvidas e quando houver interesse público. Buscando o equilíbrio entre os interesses. A quebra de privacidade consiste no acesso desnecessário ou uso de informações sem a devida autorização do indivíduo. A confidencialidade, é a ação de revelar ou deixar revelar informações fornecidas em confiança, está mais ligada as relações interpessoais. E tem os que reconhecem que exista exceções para a violação da confiança desde que haja uma permissão prévia, a lei obrigue, haja risco de vida, também na formação de estudantes na área de saúde, por equipe multiprofissional em discussão de caso clínico e quando há necessidade de interprete em caso de estrangeiros. Conclusão: Espera-se que a apresentação desses conceitos e os argumentos de possíveis violações dos princípios forneçam subsídios aos enfrentamentos dos dilemas, a fim de que possam encontrar novos caminhos e possíveis soluções para os conflitos que fazem parte do cotidiano que permeia as diversas áreas do conhecimento. Contanto que seja precedido de diálogo, argumentação, racionalidade, coerência, consenso e decisão.

AGRADECIMENTO: Programa de Pós-Graduação em Bioética Cátedra Unesco de Bioética da Universidade de Brasília - UnB

\section{REFERÊNCIAS}

[1] Garrafa V. Bioética. In: Políticas e sistema de saúde no Brasil. Giovanella L; Escorel S; Lobato LVC; Carvalho J. $2^{\text {a }}$ Ed. Rio de Janeiro: Fiocruz; 2013: 741-790.

[2] UNESCO. Declaração Universal sobre Bioética e Direitos Humanos. Tradução brasileira por Ana Tapajós e Mauro Machado do Prado, com revisão técnica de Volnei Garrafa, sob a responsabilidade da Cátedra UNESCO de Bioética da Universidade de Brasília/Sociedade Brasileira de Bioética e homologada pelo Ministério das Relações Exteriores do Brasil. Brasília, 2005. Acessível em: <https://bioetica.catedraunesco.unb.br/?page_id=250.

[3] Rotemberg M. Preserving Privacy in the Information Society. Acessível em: http://www.unesco.org/webworld/infoethics_2/eng/papers/pa per_10.htm.

[4] Kottow M. Medical confidentiality: an intransigent and absolute obligation. J MedEthics 1986; 12:117-22. Acessível em:

https://www.ncbi.nlm.nih.gov/pmc/articles/PMC1375347/pd f/jmedeth00258-0007.pdf.

[5] UNESCO. Teaching Ethics in Psychiatry: case-vignettes. Chair in Bioethics. Carmi A; Moussaoui D; Arboleda-Florez J (eds.).UNESCO: Paris, 2005.Acessível em: http://medlaw.haifa.ac.il/PUBLICAT/teaching\%20ethics $\% 20$ in\%20psych\%20new.pdf. 